Article

\title{
Condition Monitoring of Industrial Equipment Based on Multi-Variables State Estimate Technique
}

\author{
Dongteng Long ${ }^{1, * \mathbb{O}}$, Heng Zheng ${ }^{1}$ and Feng Hong ${ }^{2}$ \\ 1 China Astronautics Standards Institute, Beijing 100071, China; bitzheng@163.com \\ 2 State Key Laboratory of Alternate Electric Power System with Renewable Energy Sources, School of Control \\ and Computer Engineering, North China Electric Power University, Beijing 102206, China; \\ hongf@ncepu.edu.cn \\ * Correspondence: longdongteng@126.com; Tel.: +86-10-8810-8251
}

Received: 15 July 2020; Accepted: 10 August 2020; Published: 14 August 2020

\begin{abstract}
Unexpected failures commonly occur in industrial equipment, and condition monitoring could significantly improve the efficiency of maintenance and failure of early alarm. A condition monitoring method using multi-variables state estimate technique (MSET) is proposed, and an improved multi-variables memory matrix construction method is employed, furthermore, an analysis of comprehensive similarity index that considering variable weights is accomplished, and incipient failure alarm thresholds are determined, which lead to effective early detection of failure. The method proposed in this paper is validated using actual data for blower fan in a thermal power plant, and the simulation and comparison results are discussed. The verification results reveal that the proposed method is effective for failure monitoring modeling and achieve a superior accuracy, and incipient failure could be accurately detected.
\end{abstract}

Keywords: condition monitoring; vibration; multi-variables state estimate technique

\section{Introduction}

Industrial equipment is usually complicated and features multiple failure modes. As a large-scale rotate machine, once failure occurs, a long-time repairing, even shutdown, is required, resulting in a significant economic loss. On the other hand, industrial field characterized harsh operational environment, equipment would experience a high failure rate, therefore, accurate condition monitoring for industrial equipment is necessary, and plays a pivotal role in condition-based maintenance, which would be more beneficial than corrective and preventive maintenance [1,2].

Tavner [3] concluded the general condition monitoring for industrial equipment, including temperature, chemical emission, vibration, electrical current, and electrical discharging. Furthermore, the paper illustrated the statistics distribution of failure modes in industrial equipment in the past decades, according to the research, rotation related failure occupies nearly a half (44\%), higher than stator related $(35 \%)$ and bearing related failure $(21 \%)$, and according to previous work, unexpected vibration often occurs before serious failure events $[4,5]$.

As a typical condition monitoring parameter, vibration is chosen for example and investigated in our paper. The aim of condition monitoring is inferring the condition of equipment rapidly, and giving a clear indication for incipient failure modes using minimum measurements. In industrial fields, vibrations are directly measured, for example, vibrations data are recorded in supervisory information system (SIS) in thermal power plants. In normal operating conditions, the vibrations of different directions are controlled in a certain range. The unexpected increase of vibrations corresponds to over-load, poor lubrication, bearing loosening, rotor unbalance, or shaft bending [6]. Therefore, 
effective condition monitoring could evaluate equipment effectively, and the failures would be detected in early stage.

The state-of-the-art for rotate equipment vibration condition monitoring is concluded into directly signal monitoring and model-based monitoring. In the aspect signal analysis, time domain analysis and frequency domain analysis are effective methods for condition monitoring of rotate component vibration [6-9]. However, for large rotating equipment, such as blower fan, there are some difficult to realize signal condition monitoring: (1) blower fan working at variable power load and frequency. Working condition of rotating equipment changes frequently, which leads to frequency band width of vibration changed, resulting in poor accuracy of failure location. (2) The industrial environment is complicated, the vibration sources of each component are multiple and seriously coupling, therefore, the vibration analysis of components is difficult to reflect characteristic of blower fan. With the development and application of information technology in industrial fields, operating data, including vibration data, of equipment is recorded automatically in detail, which makes it possible to achieve condition monitoring using data-driven analysis methods. Expert system is an effective implementation for data-driven artificial intelligent method, an expert system for industrial machine vibration analysis is designed for condition monitoring, and the knowledge set was commonly constructed using operating data and laboratory and industry validation $[10,11]$. Neural network (NN) is an available method for nonlinear vibration; the model between recorded parameters and vibration state is established; the knowledge in historical data is acquired in the course of model training. The derivative neural network, such as recurrent neural network and convolutional neural network are also applied in vibration condition monitoring [12-16]. However, the weaknesses of NN are also obvious, the training process is indispensable and it is always time-consuming. Furthermore, the adequate actual failure events data are difficult to obtain in industrial fields, the labeled data are the key component for improving the vibration monitoring accuracy in model training.

A concise and effective method is establishing an exact nonlinear normal state envelope space using normal vibration data, normal operating condition is completely included in the normal state envelope space, and the distance between current condition and boundary of success envelop space is used to quantify the condition monitoring. Cempel [17] proposed vibration condition monitoring method applying symptom observation matrix; discrete observation symptom vectors were obtained by analyzing historical data, and the vectors create symptom observation matrix, using next the singular value decomposition for the given symptom observation matrix, fault symptoms could be extracted. MSET(multi-variables state estimate technique) was first proposed by Gross [18] and applied in sensor and gearbox monitoring $[19,20]$. MSET is proved as an alternative method for constructing normal state envelope space. In general, our paper focused on proposing an improved and universal condition monitoring method and judging criteria, although the vibration condition monitoring for a specific equipment is applied and discussed in our paper, obviously, the condition monitoring for the other measurement parameters for different industrial equipment, such as temperature, current, etc., could be realized by reusing the proposed method.

In this paper, the normal state envelope space construction method for industrial equipment condition monitoring is proposed based on MSET, and the variables selecting for normal state envelope space are discussed. For a further feasibility discussion, a specific application in blower fan vibration condition monitoring is proposed. The weighted-similarity between the observation vibration vector and estimated vibration vector is investigated. While the potential failure occurred, there will be distinguished difference in similarity distribution, which allows incipient failure to be detected at early stage.

The rest of paper is organized as follows: In Section 2, introduction of a typical industrial blower fan, which is applied for discussing in our research, is provided, and the parameters for blower fan are exhibited. In Section 3, the structure for vibration condition monitoring model using MSET is discussed. In Section 4, the vibration condition monitoring simulation is presented, including variables selection, model construction, similarity calculation, and alarm threshold determination. In Section 5 , 
the actual industrial data are applied for validation, and actual failure data for blower fan have been used for revealing the effectiveness of proposed method. Finally, Section 6 concludes the work.

\section{Introduction of Research Object}

A typical industrial blower fan is discussed in our research. It is manufactured by TLT Cooperation, equipped in a thermal power plant in northern China, used for conveying air into furnace of boiler for combustion. The blades of blower fan are integrated with driving motor by shaft, and the shaft is sustained by bearings. While the motor is running, the blades rotate and air is injected into the furnace of the boiler. The structure for blower fan is shown in Figure 1, and the actual layout and location of measuring points for investigated blower fan are also exhibited.

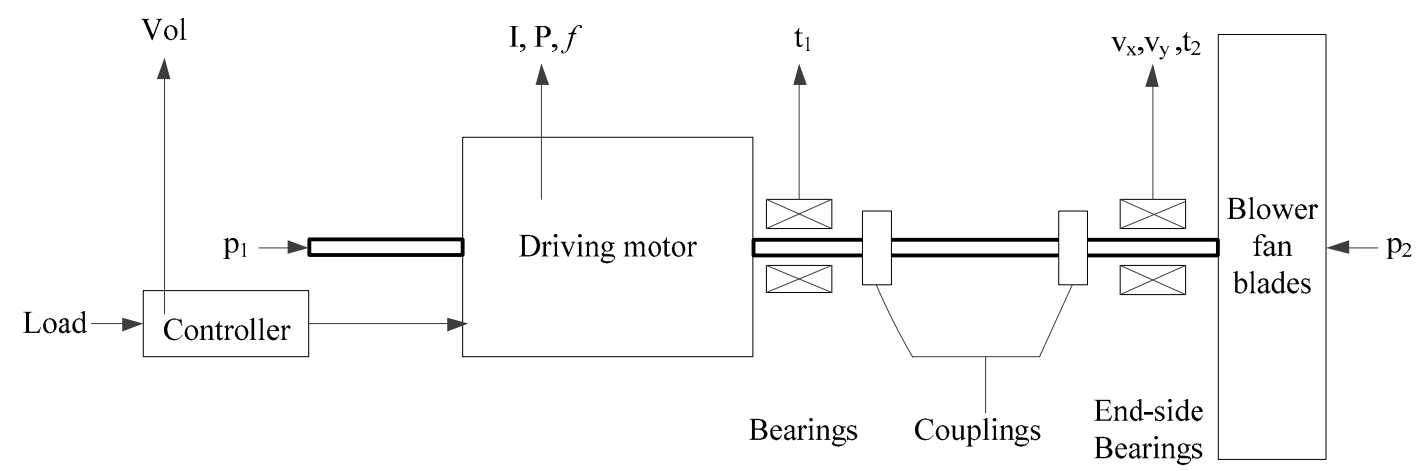

Figure 1. Layout of the blower fan.

The Supervisory Information System (SIS) for the power plant records the parameters for blower fan in a 20-s sampling solution. In each sample, related parameters include: time stamp, current air volume, load of unit, vibration of bearings, temperature of bearings, current of driving motor, operation frequency of driving motor, and power of driving motor. The parameters are shown in Table 1. Particularly, the temperature values, including temperature of bearings and end-side bearings, are measured using platinum resistance temperature detector. Before variables selection for condition monitoring, the 2 out of 3 actions are accomplished, the absolute errors between each of the two temperature values are compared, and the average of temperatures whose absolute error is smallest is regard as the actual value of measurement, which would improve the reliability of the measurement.

Except the parameters, the actual vibration alarms were also recorded in Supervisory Information System; while the vibration values exceed the thresholds setting ahead, the time stamp is recorded. The 7-day normal condition data are available for modeling. Meanwhile, actual failure alarms are acquired in our investigated blower fan, which is used for incipient failure detecting validation in our papers.

Table 1. Parameter of blower fan.

\begin{tabular}{cccc}
\hline Parameter & Remark & Quantity & Unit \\
\hline Load & Current Load of the Unit & 1 & $\%$ \\
Vol & Current Air Volume of Unit & 1 & $\%$ \\
$\mathrm{I}$ & Current of Driving Motor & 1 & $\mathrm{~A}$ \\
$\mathrm{P}$ & Power of Driving Motor & 1 & $\mathrm{~kW}$ \\
$f$ & Operation Frequency of Driving Motor & 1 & $\mathrm{~Hz}$ \\
$\mathrm{t}_{1}$ & Temperature of Bearings & 3 & ${ }^{\circ} \mathrm{C}$ \\
$\mathrm{t}_{2}$ & Temperature of End-Side Bearings & 3 & ${ }^{\circ} \mathrm{C}$ \\
$\mathrm{v}_{\mathrm{x}}$ & Vibration of Horizontal & 1 & $\mathrm{~mm} / \mathrm{s}$ \\
$\mathrm{v}_{\mathrm{y}}$ & Vibration of Vertical & 1 & $\mathrm{~mm} / \mathrm{s}$ \\
$\mathrm{p}_{1}$ & Inlet Air Pressure & 1 & $\mathrm{~Pa}$ \\
$\mathrm{p}_{2}$ & Furnace Pressure & 1 & $\mathrm{~Pa}$ \\
\hline
\end{tabular}




\section{Multi-Variable State Estimate Technique (MSET)}

By applying MSET, considerable historical data for industrial equipment are used for constructing the normal state envelope space, which is noted as memory matrix $D$. While the industrial equipment operating, the measurement parameters are observed real-time, and the related $n$ parameters construct a vector noted as $\boldsymbol{X}_{o b s}$. In the time sample $j$, the observation vector is written as,

$$
X\left(t_{j}\right)=\left[x_{1}\left(t_{j}\right), x_{2}\left(t_{j}\right), \ldots, x_{n}\left(t_{j}\right)\right]^{T}
$$

It should be pointed out that for different equipment condition monitoring, only the parameters and thresholds need to be determined if reusing the proposed method, and the complete preprocess of the case study in our paper is posed in Section 4.

$D$ is an $m \times n$ dimension matrix, which means $m$ normal samples are strictly selected and contained in $\boldsymbol{D}$ at last. Comprehensive operating conditions, including high load, low load, change load, and other operating conditions should be contained. Memory matrix $D$ could be written as,

$$
D=\left[\begin{array}{llll}
X\left(t_{1}\right) & X\left(t_{2}\right) & \cdots & X\left(t_{m}\right)
\end{array}\right]=\left[\begin{array}{cccc}
x_{1}\left(t_{1}\right) & x_{1}\left(t_{2}\right) & \cdots & x_{1}\left(t_{m}\right) \\
x_{2}\left(t_{1}\right) & x_{1}\left(t_{2}\right) & \cdots & x_{2}\left(t_{m}\right) \\
\vdots & \vdots & \vdots & \vdots \\
x_{n}\left(t_{1}\right) & x_{n}\left(t_{2}\right) & \cdots & x_{n}\left(t_{m}\right)
\end{array}\right]_{n \times m}
$$

The vectors included in the memory matrix $\boldsymbol{D}$ construct a nonlinear normal state envelope space. After the memory matrix $\boldsymbol{D}$ constructed, dynamic state estimation could be accomplished by applying it.

The construction of estimation vector for the same time sample $\boldsymbol{X}_{\text {est }}$ is constructed by the vectors in memory matrix $\boldsymbol{D}$, the different of $\boldsymbol{X}_{\text {est }}$ and $\boldsymbol{X}_{o b s}$ is applied for condition monitoring. $\boldsymbol{X}_{\text {est }}$ could be written as,

$$
\begin{aligned}
X_{\text {est }} & =D \cdot W=D \cdot\left[\begin{array}{llll}
w_{1} & w_{2} & \cdots & w_{m}
\end{array}\right]^{T} \\
& =w_{1} X\left(t_{1}\right)+w_{2} X\left(t_{2}\right)+\cdots+w_{m} X\left(t_{m}\right)
\end{aligned}
$$

The weight matrix $W$ stands for similarity between observation vector and components in matrix $D$. The optimized weight matrix W could be obtained by minimizing the error between $X_{\text {est }}$ and $X_{o b s}$, which is,

$$
e=X_{e s t}-X_{o b s}
$$

According to the least square algorithm, for minimizing $\|e\|_{2}$ let,

$$
\begin{gathered}
S(w)=\sum_{i=i}^{n} e_{i}^{2}=e^{T} e=\left(X_{o b s}-X_{e s t}\right)^{T} \cdot\left(X_{o b s}-X_{e s t}\right) \\
=\left(X_{o b s}-D \cdot W\right)^{T} \cdot\left(X_{o b s}-D \cdot W\right)=\sum_{i=1}^{n}\left(X_{o b s}(i)-\sum_{j=1}^{m} w_{j} D_{i j}\right)^{2}
\end{gathered}
$$

where, $D_{i j}$ is the element for memory matrix in $i$ line $j$ column.

Solving the partial derivative Equation for $w_{\mathrm{i}}$ in $S(w)$, which is,

$$
\frac{\partial S}{\partial w_{k}}=-2 \sum_{i=1}^{n}\left(X_{o b s}(i)-\sum_{j=1}^{m} w_{j} D_{i j}\right) D_{i k}=0
$$

That is,

$$
\sum_{i=1}^{n} X_{o b s}(i) D_{i k}=\sum_{i=1}^{n} \sum_{j=1}^{m} w_{j} D_{i j} D_{i k}=\sum_{i=1}^{n}\left(\sum_{j=1}^{m} D_{i j} D_{i k}\right) w_{j}
$$


The Equation (7) could be expressed as matrix form as,

$$
D^{T} \cdot D \cdot W=D^{T} \cdot X_{o b s}
$$

The weight matrix could be solved, that is,

$$
W=\left(D^{T} \cdot D\right)^{-1} \cdot\left(D^{T} \cdot X_{o b s}\right)
$$

In particular, if components in memory matrix $\boldsymbol{D}$ are linear correlative, the matrix $D^{T} \cdot D$ would be irreversible, which leads the (9) unsolvable. In order to solve the problem properly, there are many alternative operator; Argonne laboratory has also developed a unique algorithm for nonlinear calculation [15]. A nonlinear operator $\otimes$ is introduced, and the Equation (9) could be written as,

$$
W=\left(D^{T} \otimes D\right)^{-1} \cdot\left(D^{T} \otimes X_{o b s}\right)
$$

Concise nonlinear operator that calculates the Euclidean distance arithmetic is chosen in our paper, that is,

$$
\otimes(X, Y)=\sqrt{\sum_{i=1}^{n}\left(x_{i}-y_{i}\right)^{2}}
$$

The operator we employed is easy to understand physically, and the similarity of two vectors is represented by spatial distance. If the observation vector is similar with the vectors in memory matrix $D$, the corresponding spatial distances would be small, and while there is a distinguishable different between observation vector and memory matrix, the distance would become large. Finally, the estimation vector could be written as,

$$
X_{e s t}=D \cdot\left(D^{T} \otimes D\right)^{-1} \cdot\left(D^{T} \otimes X_{o b s}\right)
$$

The memory matrix $\boldsymbol{D}$ established a normal nonlinear normal state envelope space, while the input observation vector $\boldsymbol{X}_{o b s}$ is located in the normal space and similar with a vector in $\boldsymbol{D}$, the corresponding vector $\boldsymbol{X}_{\text {est }}$ obtained by Equation (12) is rather accurate. However, if an incipient failure occurs, the characteristic of $\boldsymbol{X}_{o b s}$ would change, and the observation vector $\boldsymbol{X}_{o b s}$ would exceed the boundary of envelope space, as a result, $\boldsymbol{X}_{o b s}$ could not be represented by using the vectors included in memory matrix $\boldsymbol{D}$, and the current observation vector $\boldsymbol{X}_{o b s}$ and the estimate vector $\boldsymbol{X}_{\text {est }}$ would be very different. In conclusion, the incipient failure could be detected by analyzing similarity between $\boldsymbol{X}_{\text {obs }}$ and $\boldsymbol{X}_{\text {est }}$.

\section{Modeling Description}

\subsection{Data Preprocess and Variables Selection}

Data preprocess is an important stage in the data-driven modeling. Normally, missing values and outliers, should be removed or specially dealt with. In our research, the outliers and missing values are replaced by the average of the adjacent samples to guarantee the data continuity. On the other hand, the dimensional difference of input and output variables is eliminated by data standardization using Equation (13), which transforms different variables to same scale.

$$
x^{\prime}=\frac{x-\bar{x}}{\sigma}
$$

Before constructing the memory matrix, the variables need to be selected. Vibration variables are target vectors, and the relationship between the other variables is listed in Table 1 and target vectors need to be discussed. Grey relational analysis is an effective statistical method quantifying the relevance degrees, the "grey relational degree" of variables is calculated using consecutive data 
of variables, and the method is proved effective in many fields. Therefore, grey relational analysis is applied in variables selection in our paper.

Consecutive 1000 samples are used for obtaining grey relational degree. Vibration vectors are set as target sequences, and the rest 9 variables are set as comparing vectors. The grey relational degree sequence for variable could be calculated as,

$$
\xi_{i}(k)=\frac{\min _{i} \min _{k}\left|y(k)-x_{i}(k)\right|+\rho \max _{i} \max _{k}\left|y(k)-x_{i}(k)\right|}{\left|y(k)-x_{i}(k)\right|+\rho \max _{i} \max _{k}\left|y(k)-x_{i}(k)\right|}
$$

where, $\rho$ is discrimination coefficient, and is set as 0.6 in our research.

The average grey relational degrees for compared vector are calculated as,

$$
r_{i}=\frac{1}{n} \sum_{k=1}^{n} \xi_{i}(k)
$$

The results of grey relational analysis between the horizontal vibration, vertical vibration, and the compared vector are shown in Tables 2 and 3, respectively. According to the grey relational analysis results, except the vibration of horizontal and vertical itself, the temperature of end-side bearings, current air volume of unit, operation frequency of driving motor and current of driving motor (gray relational degree $>0.6$ ), are chosen for vibration condition monitoring.

Table 2. Results of grey relational analysis for horizontal vibration.

\begin{tabular}{ccc}
\hline Parameter & Remark & Gray Relational Degree \\
\hline $\mathrm{t}_{2}$ & Temperature of End-Side Bearings & 0.913 \\
Vol & Current Air Volume of Unit & 0.844 \\
$f$ & Operation Frequency of Driving Motor & 0.819 \\
$\mathrm{I}$ & Current of Driving Motor & 0.789 \\
Load & Current Load of The Unit & 0.595 \\
$\mathrm{p}_{2}$ & Furnace Pressure & 0.549 \\
$\mathrm{P}$ & Power of Driving Motor & 0.417 \\
$\mathrm{t}_{1}$ & Temperature of Bearings & 0.355 \\
$\mathrm{p}_{1}$ & Inlet Air Pressure & 0.191 \\
\hline
\end{tabular}

Table 3. Results of grey relational analysis for vertical vibration.

\begin{tabular}{ccc}
\hline Parameter & Remark & Gray Relational Degree \\
\hline$f$ & Operation Frequency of Driving Motor & 0.847 \\
$\mathrm{I}$ & Current of Driving Motor & 0.739 \\
$\mathrm{t}_{2}$ & Temperature of End-Side Bearings & 0.733 \\
$\mathrm{P}$ & Power of Driving Motor & 0.719 \\
$\mathrm{Vol}$ & Current Air Volume of Unit & 0.627 \\
$\mathrm{p}_{1}$ & Inlet Air Pressure & 0.514 \\
$\mathrm{t}_{1}$ & Temperature of Bearings & 0.419 \\
Load & Current Load of The Unit & 0.261 \\
$\mathrm{p}_{2}$ & Furnace Pressure & 0.167 \\
\hline
\end{tabular}

\subsection{Vector Selection for Memory Matrix}

While the MSET was first proposed, the $\boldsymbol{D}$ is constructed by the extreme vectors for each parameter, and the boarder of normal state envelope space is defined by the extreme vectors. In latest works, vectors of normal condition are added to memory matrix according to constant interval and access criteria, indeed, the method improved the memory matrix $\boldsymbol{D}$ and enhanced the ability for describing normal conditions. However, special normal condition vector might be omitted in sample process, 
which would seriously affect the prediction performance. Thus, a novel normal vectors selection method using self-adaption access criteria is proposed. After standardization, the deviation degree is reflected by the distance between normal vector with origin point in hyperplane. Because the vectors for memory matrix is selected in normal condition, the vectors are relatively intensive in the area that is close to the origin point in hyperplane, and in the area relatively far from the origin point, vectors are sparse and special normal condition often appears. The special normal condition vector might not be selected by using the constant interval and access criteria sampling method.

In order to select representative normal vector and retain some special normal vector, the sample access criteria change with probability density function, while the value of function is small, which means the vector is located in sparse area in hyperplane, the access criteria is relatively loose for introducing more special normal vectors. As shown in Figure 2, the maximum of probability density function is 0.62 . The number of vector in memory matrix $D$ is set as 200 . The procedure for constructing memory matrix $\boldsymbol{D}$ is formulated in Figure 3.

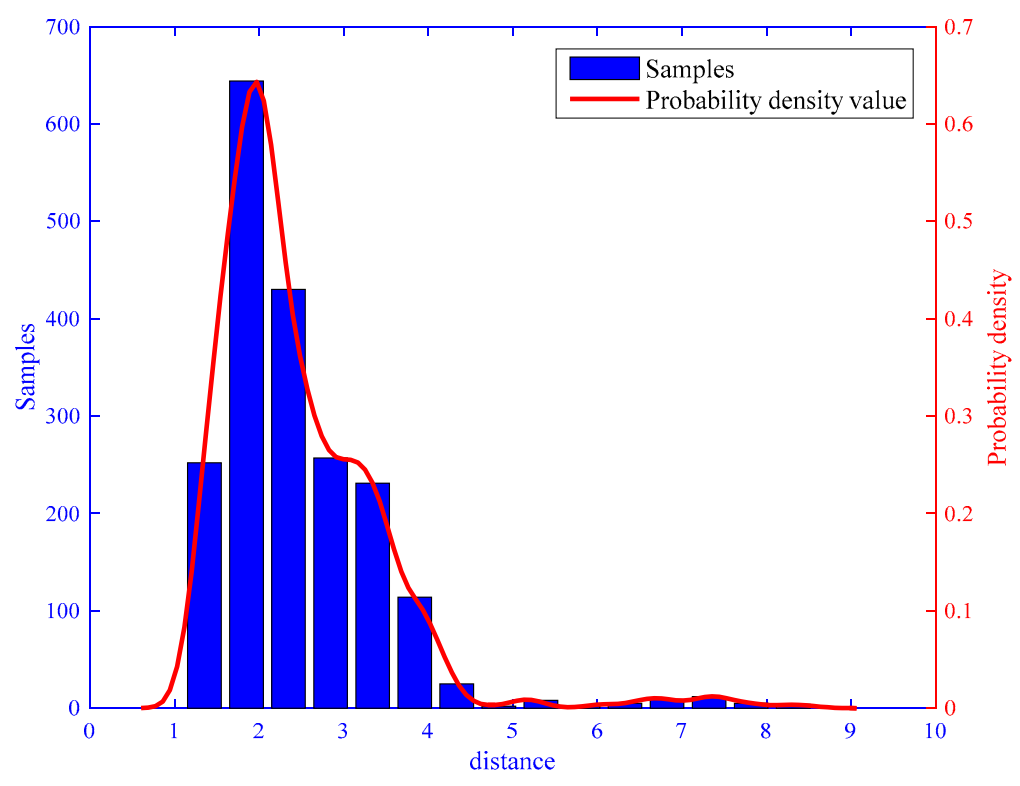

Figure 2. Fitting for probability density function. 


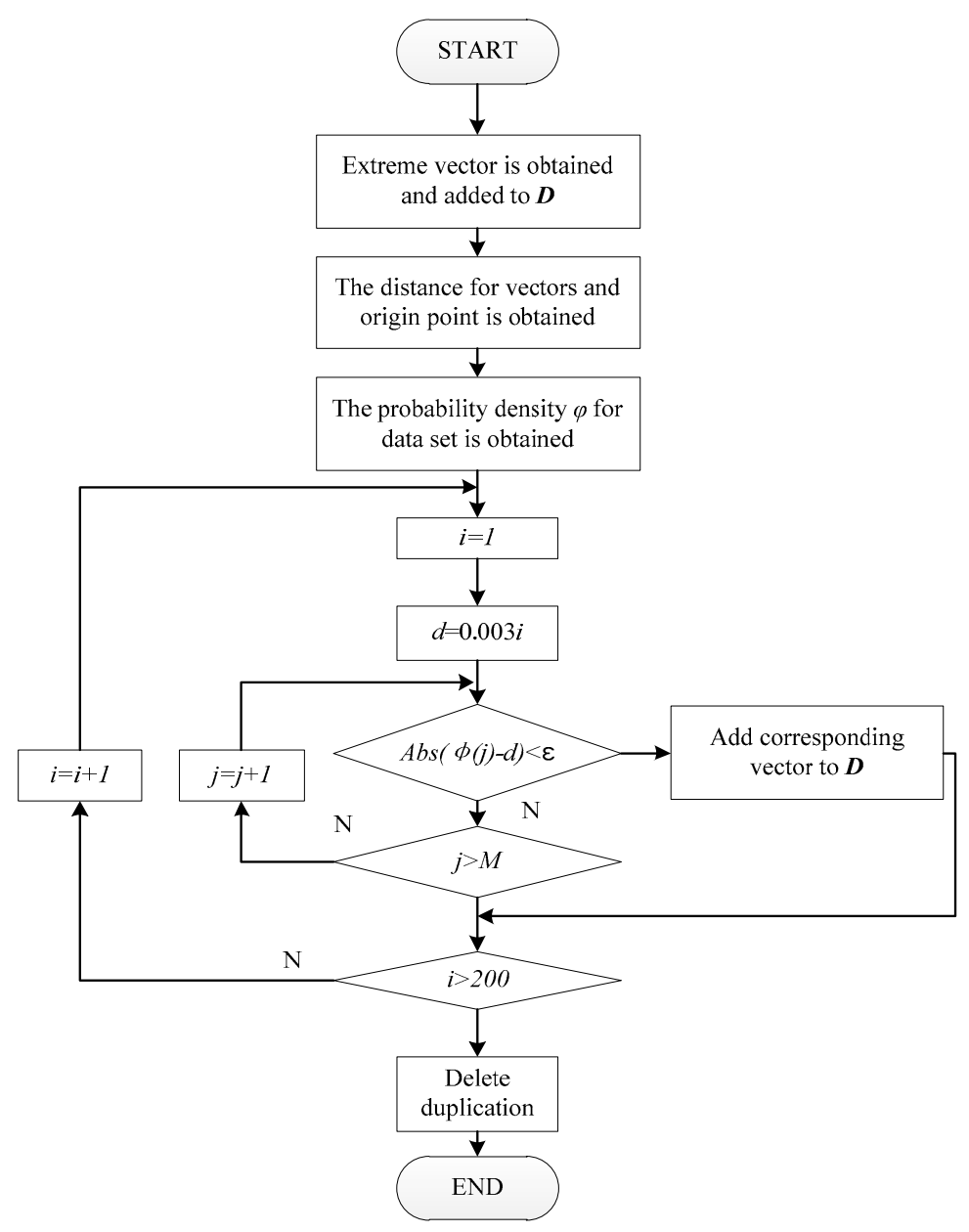

Figure 3. Procedure for constructing memory matrix D.

Where,

$$
\varepsilon=\frac{k}{\varphi(j)}
$$

$k$ is an empirical parameter, and is set as 0.0015 in our simulation.

\subsection{Improved Similarity Calculation}

The residual of vibrations component in $\boldsymbol{X}_{\text {obs }}$ and $\boldsymbol{X}_{\text {est }}$, including the average value for residual sequence, are usually used for judging whether the incipient failures occur in previous works. However, the information contained in the other variables, including temperature of end-side bearings, current air volume of unit, operation frequency of driving motor, and current of driving motor, would be neglected, but some vibrations failure might be first reflected by indirect parameters. Therefore, except the analysis the residual of vibrations directly, a comprehensive similarity calculation based on other components in observation vector is proposed, and the difference between components is considered.

The similarity could be formulated as,

$$
S\left(X_{o b s}, X_{e s t}\right)=\frac{1}{1+\sqrt{\sum_{i=1}^{n} R_{i}\left[X_{o b s, i}(t(k))-X_{e s t, i}(t(k))\right]^{2}}}
$$


where $X_{o b s, i}$ and $X_{e s t, i}$ are the component $i$ in observation vector and estimation vector, respectively, and $R_{i}$ is corresponding weight coefficient for $i$ component in vectors, which could be obtained according to the result of grey relational analysis in Table 4 .

$$
R_{i}=\frac{r_{i}}{\sum_{j}^{n} r_{j}}
$$

where $n$ is the number of components that are selected in to memory matrix.

Table 4. Comparison of RMSE and MAPE for condition I.

\begin{tabular}{cccc}
\hline \multicolumn{2}{c}{ Situation } & RMSE (mm/s) & MAPE (\%) \\
\hline \multirow{2}{*}{ Horizontal vibration $x_{1}$} & Proposed method & 0.0045 & 0.45 \\
\cline { 2 - 4 } & Traditional method & 0.0265 & 2.12 \\
\hline \multirow{2}{*}{ Vertical vibration $x_{2}$} & Proposed method & 0.0017 & 0.11 \\
\cline { 2 - 4 } & Traditional method & 0.0177 & 2.79 \\
\hline
\end{tabular}

\subsection{Incipient Failure Threshold Determination}

\subsubsection{Residual Threshold}

Residual threshold is determined for residuals between $\boldsymbol{X}_{o b s}$ and $\boldsymbol{X}_{\text {est }}$, and it is a direct vibration monitoring parameter, information contained in vibration component of observation vector is applied. In order to reflect the long-term trend of vibration monitoring and eliminate the influence of measurement errors, residuals sequence is discussed and sliding window is applied. The threshold of average value $T_{\text {aver }}$ is defined as,

$$
T_{\text {aver }}=\left|c_{1} \cdot A V E R\right|
$$

where $A V E R$ is the average residual in a sliding window. The current residual is compared with $T_{\text {aver }}$. The coefficient $c_{1}$ is determined by operation experience and validation, in this paper, $c_{1}=2.5$.

\subsubsection{Similarity Threshold}

As a supplement for direct vibration monitoring, information contained in the other component in $\boldsymbol{X}_{o b s}$ and $\boldsymbol{X}_{\text {est }}$ are applied to calculate a comprehensive similarity, which is significant for detecting faults reflecting in indirect variables. Furthermore, as shown in Figure 1 and Table 1, there are no redundancies for vibration measurement, therefore, similarity judgement is an effective way in situations where vibrating measurement fails, and it is significant for improving the accuracy of condition monitoring. The similarity threshold could be formulated as,

$$
T_{s}=\frac{S\left(X_{o b s}, X_{e s t}\right)_{\min }}{c_{2}}
$$

where $S\left(X_{o b s}, X_{e s t}\right)$ min is the minimum of similarity in a sliding window, and coefficient $c_{2}$ is set as 1.1 in this paper.

\section{Validation and Discussion}

\subsection{Validation of Blower Fan MSET Modeling}

The sample solution of data is 20 seconds, and the variables we discussed in Section 4 is available, which are vibration of horizontal $x_{1}$, vibration of vertical $x_{2}$, the temperature of end-side bearings $x_{3}$, current air volume of unit $x_{4}$, operation frequency of driving motor $x_{5}$, current of driving motor $x_{6}$, respectively. The typical distribution for normal data in 10/25/2015 is shown in Figure 4, the maximum 
of vibration in horizontal and vertical direction are $2.725 \mathrm{~mm} / \mathrm{s}$ and $5.195 \mathrm{~mm} / \mathrm{s}$, respectively. In totally, 7 days normal samples were used for contrasting memory matrix $D$.

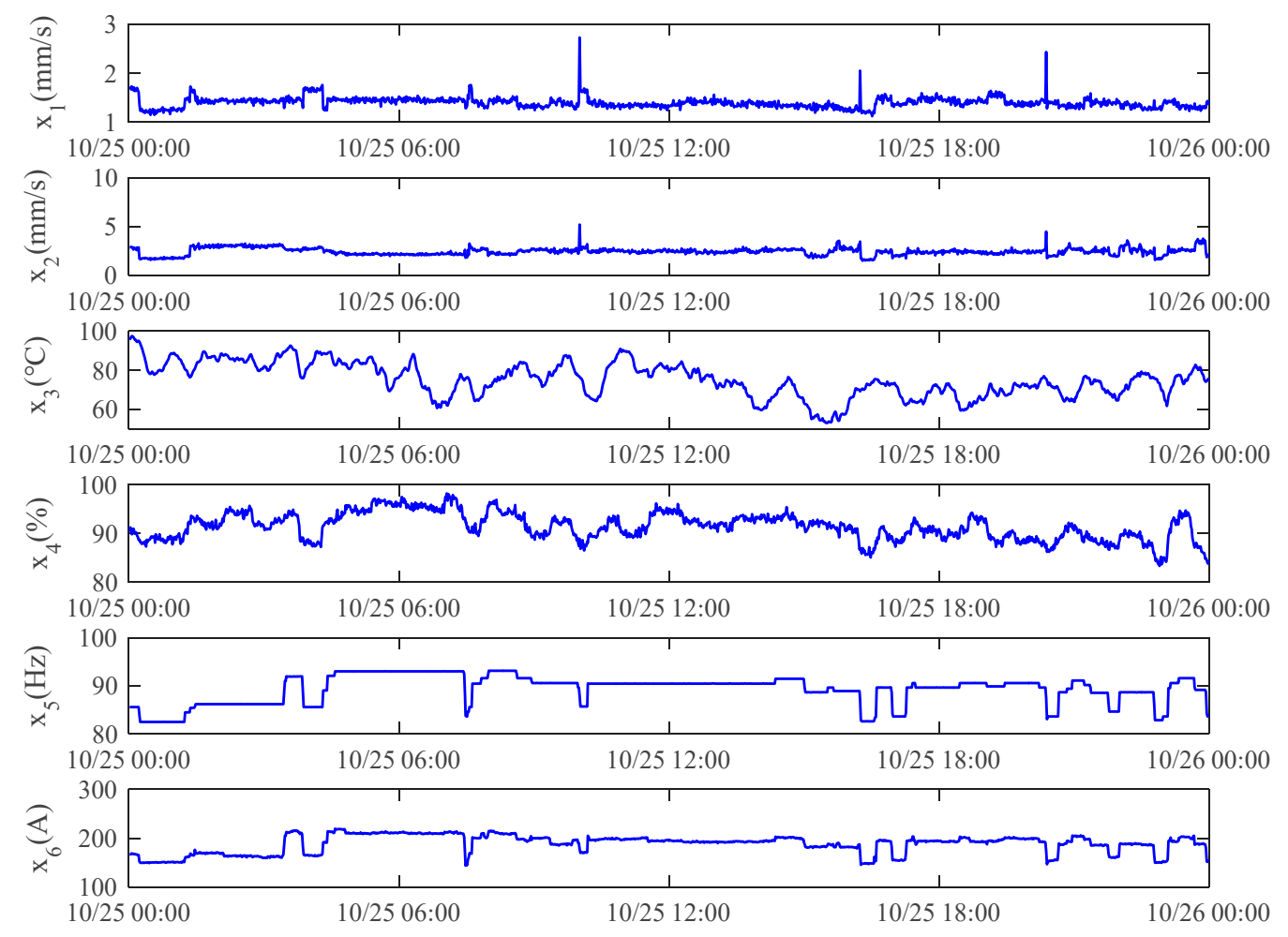

Figure 4. Layout of variables data.

After using the method mentioned in Section 4, memory matrix $\boldsymbol{D}$ is constructed, and 211 vectors are concluded, therein, 11 vectors are selected by extreme condition of 6 variables and remove duplication, and the rest 200 vectors are obtained by method mentioned in Figure 3. Consecutive normal samples, including steady and dynamic working condition data, are used for validating the accuracy of MEST model.

\subsubsection{Steady Working Condition}

In order to validate the effectiveness of the proposed method, traditional constant interval and access criteria method [18] are applied for comparison, which is shown as traditional method in the figures, and the size of memory matrix is also set as 200. It should be pointed out that in traditional method, the access criteria $\varepsilon$ is a constant, and extreme condition vectors are also included in traditional method. The comparisons for proposed method and traditional method of horizontal and vertical vibration are shown in Figures 5 and 6, respectively, and the residual and similarity are compared.

The dataset for validation in Figures 5 and 6 is relative steady and chosen from a normal working condition for blower fan, named normal condition I. 

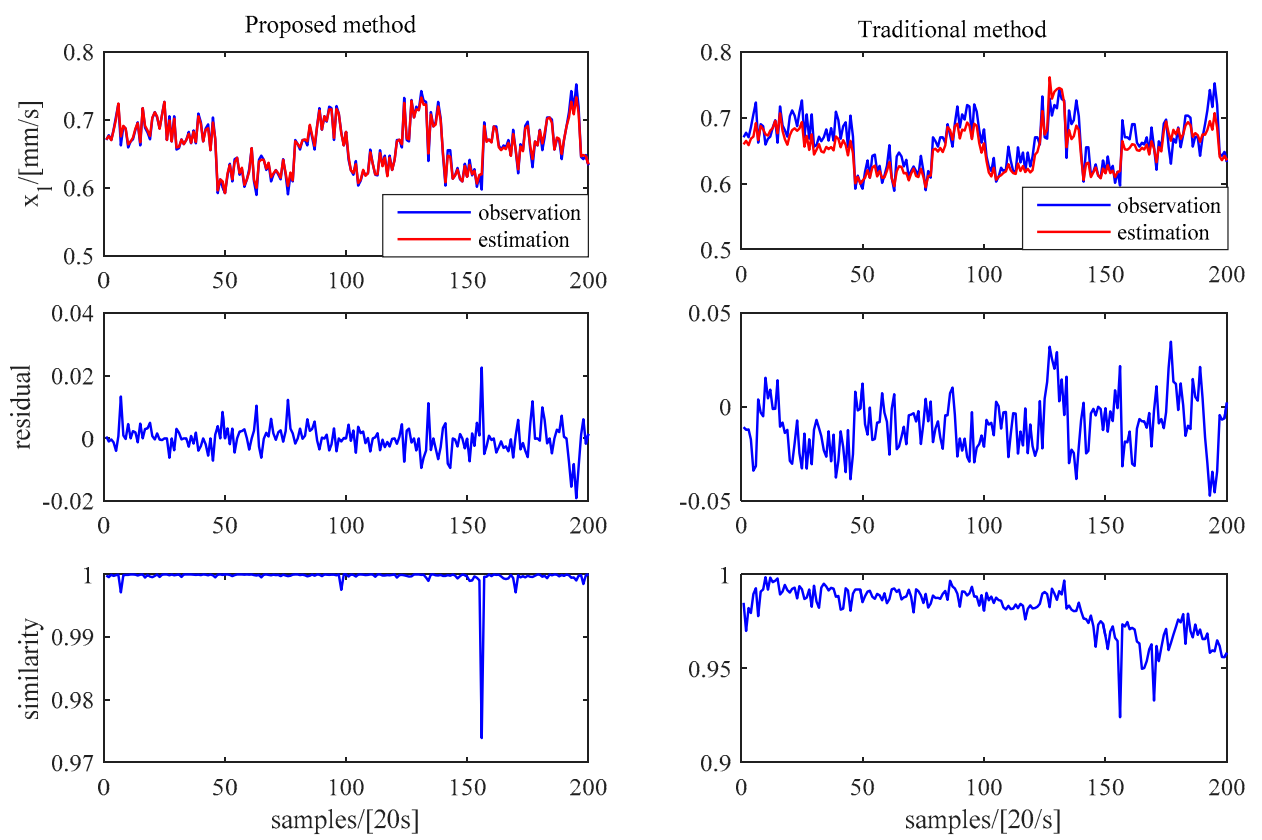

Figure 5. Comparison for proposed method and traditional method for horizontal vibration in condition I.
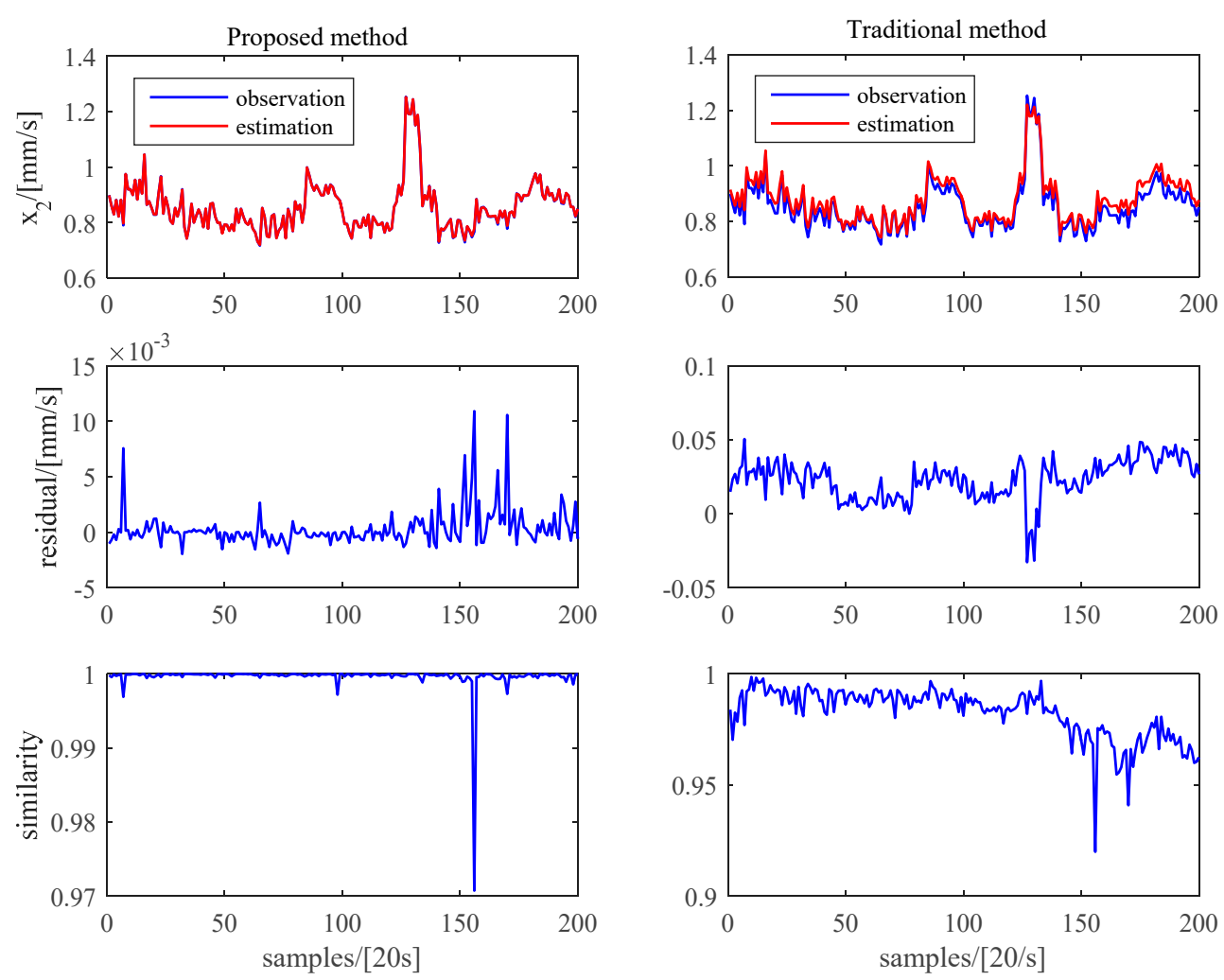

Figure 6. Comparison for proposed method and traditional method for vertical vibration in condition I.

As shown in Figures 5 and 6, the ranges for horizontal and vertical vibrations are $0.589 \mathrm{~mm} / \mathrm{s}$ to $0.752 \mathrm{~mm} / \mathrm{s}$ and $0.717 \mathrm{~mm} / \mathrm{s}$ to $1.253 \mathrm{~mm} / \mathrm{s}$, respectively, which are normal vibration ranges. The vibrations in the dataset are steady, and in that condition, the residuals comparing results reveal the advantage of the proposed method, the horizontal vibration or vertical vibration. The average absolute values of residuals for the proposed method for horizontal and vertical vibrations are $0.003 \mathrm{~mm} / \mathrm{s}$ 
and $8.73 \times 10^{-4} \mathrm{~mm} / \mathrm{s}$, respectively, that for traditional method are $0.0143 \mathrm{~mm} / \mathrm{s}$ and $0.0238 \mathrm{~mm} / \mathrm{s}$, respectively. The similarity obtained according to Equation (17) also reflects the advantage of the proposed method, the similarity for the proposed method is above 0.97 , including horizontal and vertical vibrations, that for most of samples are over 0.999 , and the results for similarity comparisons prove the advantage of proposed method.

For comprehensively evaluating the ability of characterizing normal state envelope space, the root mean square error (RMSE) and MAPE (mean absolute percentage error) are applied for comparison, the calculating formula are,

$$
\begin{aligned}
& \text { RMSE }=\sqrt{\frac{\sum_{i=1}^{n}\left(y_{i}-\hat{y}_{i}\right)^{2}}{n}} \\
& M A P E=\frac{1}{n} \sum_{i=1}^{n}\left|\frac{y_{i}-\hat{y}_{i}}{y_{i}}\right|
\end{aligned}
$$

where $y_{i}$ and $\hat{y}_{i}$ are observation and estimation values, respectively.

The RMSE and MAPE comparison of proposed method and traditional method for normal condition I is shown in Table 4. In normal condition I, the RMSE and MAPE for proposed method of horizontal vibration $x_{1}$ are $0.0045 \mathrm{~mm} / \mathrm{s}$ and $0.45 \%$, respectively, that for traditional method are 0.0265 $\mathrm{mm} / \mathrm{s}$ and $2.12 \%$, respectively. For vertical vibration $x_{2}$, the RMSE and MAPE for proposed method are $0.0017 \mathrm{~mm} / \mathrm{s}$ and $0.11 \%$, that for traditional method are $0.0177 \mathrm{~mm} / \mathrm{s}$ and $2.79 \%$, respectively. The results reveal that while in a relative steady normal condition, the proposed method achieves a better estimation performance.

\subsubsection{Dynamic Working Condition}

In order to further validate the effectiveness of the proposed method, the horizontal and vertical vibrations for blower fan in dynamic work condition, named condition II, are applied. The comparison for proposed method and traditional method in condition II is shown in Figures 7 and 8.
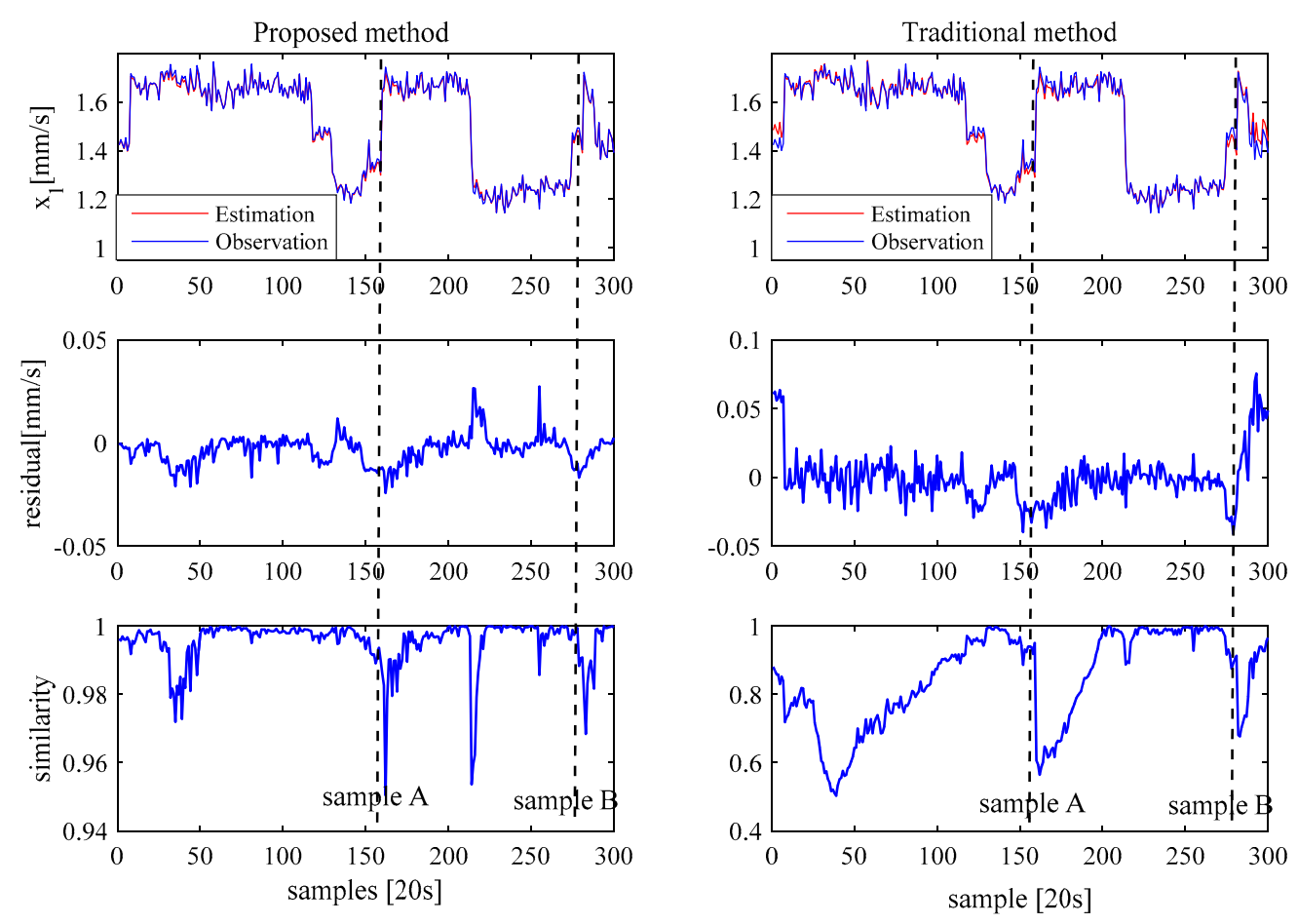

Figure 7. Comparison for proposed method and traditional method for horizontal vibration condition II. 

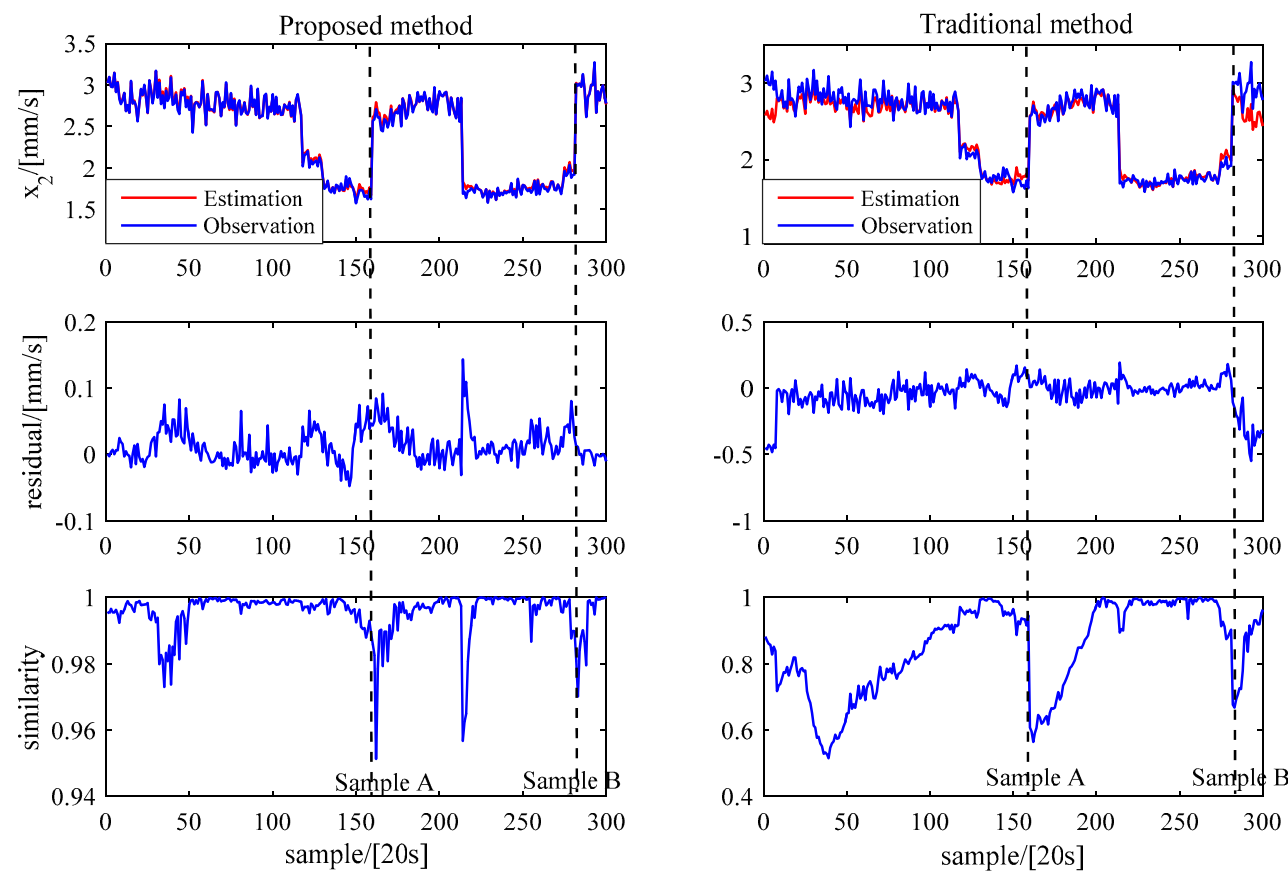

Figure 8. Comparison for proposed method and traditional method for vertical vibration condition II.

As shown in Figure 7, the horizontal vibration of test data set is change in the range of $1.144 \mathrm{~mm} / \mathrm{s}$ to $1.767 \mathrm{~mm} / \mathrm{s}$, which is the normal vibrating range according to engineering handbook. Comparing the residual results, the proposed method achieves a higher accuracy, the residual is contained in $-0.0243 \mathrm{~mm} / \mathrm{s}$ to $0.0274 \mathrm{~mm} / \mathrm{s}$, which for traditional method is $-0.0411 \mathrm{~mm} / \mathrm{s}$ to $0.0756 \mathrm{~mm} / \mathrm{s}$.

It should be pointed out that the condition changed obviously at certain samples, such as sample A and sample B marked in the Figure, and the condition changes do not reflect in residuals obviously, however, the similarity reveals the condition changes accurately, at the sample A and sample B, the vibrate condition changes and similarity descends correspondingly. Owning to the calculation of the other variables in observation vector, information except direct vibration variables is contained in similarity calculation, which is significant for a comprehensive vibration condition monitoring.

As shown in Figure 8, the vertical vibration of test dataset is changed in the range of $1.573 \mathrm{~mm} / \mathrm{s}$ to $3.273 \mathrm{~mm} / \mathrm{s}$, which is also a normal vibrating range, and the trend for vertical vibration is similar with horizontal vibration. The ranges for residual for proposed method and traditional method are $-0.048 \mathrm{~mm} / \mathrm{s}$ to $0.1434 \mathrm{~mm} / \mathrm{s},-0.5495 \mathrm{~mm} / \mathrm{s}$ to $0.192 \mathrm{~mm} / \mathrm{s}$, respectively, and the results reveal that the proposed method achieve a higher estimation accuracy.

The RMSE and MAPE for condition II is shown in Table 5. For horizontal vibration $x_{1}$, the RMSE and MAPE of the proposed method are $0.0077 \mathrm{~mm} / \mathrm{s}$ and $0.36 \%$, respectively, that for traditional method are $0.0189 \mathrm{~mm} / \mathrm{s}$ and $0.85 \%$, respectively. For vertical vibration $x_{2}$, the RMSE and MAPE for the proposed method are $0.0293 \mathrm{~mm} / \mathrm{s}$ and $0.94 \%$, that for the traditional method are $0.1323 \mathrm{~mm} / \mathrm{s}$ and $3.33 \%$, respectively. The results reveal that while in dynamic normal condition, the proposed method keeps a superior estimation performance.

Table 5. Comparison of RMSE and MAPE for condition II.

\begin{tabular}{cccc}
\hline \multicolumn{2}{c}{ Situation } & RMSE (mm/s) & MAPE (\%) \\
\hline \multirow{2}{*}{ Horizontal vibration $x_{1}$} & Proposed Method & 0.0077 & 0.36 \\
\cline { 2 - 4 } & Traditional Method & 0.0189 & 0.85 \\
\hline \multirow{2}{*}{ Vertical vibration $x_{2}$} & Proposed Method & 0.0293 & 0.94 \\
\cline { 2 - 4 } & Traditional Method & 0.1323 & 3.33 \\
\hline
\end{tabular}




\subsection{Incipient Failure Detection}

According to the operation handbook, the vibration conditions often evaluated by measuring values directly, the vibration alarm is not triggered until the vibration measure values exceed the threshold, therefore, an early alarm could not be realized, and the condition judgment criteria is shown in Table 6, which means once the vibration measurements exceed $5.1 \mathrm{~mm} / \mathrm{s}$, the alarm occurs.

Table 6. The vibration threshold for investigated blower fan.

\begin{tabular}{ccc}
\hline Alarm Level & Vibration Measurement & Condition \\
\hline$/$ & $X \leq 5.1 \mathrm{~mm} / \mathrm{s}$ & Normal \\
I & $5.1 \mathrm{~mm} / \mathrm{s}<x \leq 7.1 \mathrm{~mm} / \mathrm{s}$ & Carry out operations, maintenance if necessary \\
II & $X>7.1 \mathrm{~mm} / \mathrm{s}$ & Immediately shutdown and maintenance \\
\hline
\end{tabular}

The exceed-threshold events could be detected by an effective failure early detection, and the incipient failure thresholds for residual and similarity proposed in 4.4 are applied. As shown in Figure 9, the typical vertical vibration alarm events are discussed, and the process is exhibited, residual and similarity are shown correspondingly. There are two vibration alarms in the process, noted as alarm 1 and alarm 2, respectively. According to the data records, the timelines for the event are:

- Sample 1 Sample 123: Normal

- Sample 124 (2015/11/25 14:01:00): vertical vibration exceeds threshold (5.75 mm/s)

- Sample 139 (2015/11/25 14:06:00): check vibration status and adjust the air volume

- Sample 151 (2015/11/25 14:10:00): vertical vibration recovery

- Sample 152 275: Normal

- Sample 276 (2015/11/25 14:51:40) vertical vibration exceeds threshold (5.20 mm/s)
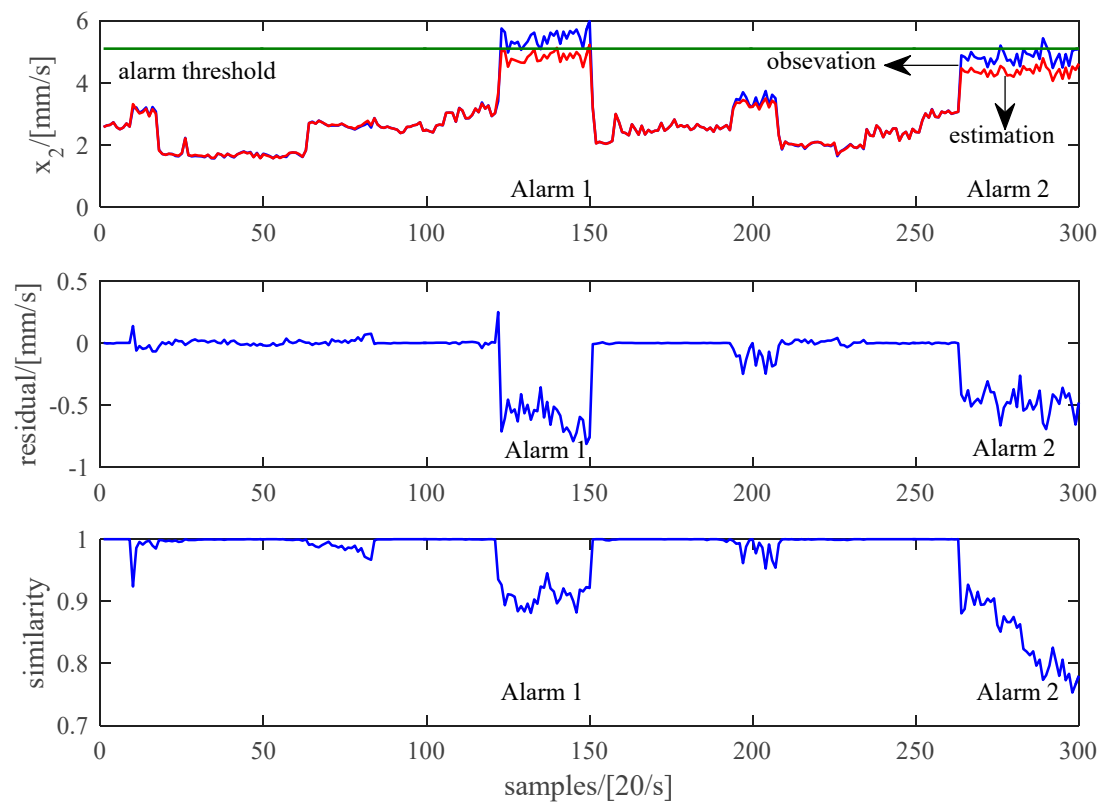

Figure 9. Process of typical vertical vibration alarm event.

The size of sliding window is set as 10, and the effectiveness of residual threshold and similarity threshold are validated in the alarms. The thresholds, current value, and corresponding sample for alarms are compared in Table 7. In the alarm 1, the actual alarm is NO.124 sample, and the failure alarm is earlier detected in NO.120 sample and NO.121 sample by using residual threshold and similarity threshold, respectively, and the failure could be detected 1 minute ahead. Furthermore, in the alarm 2, 
the actual alarm is NO.276 sample, in comparison, the failure alarm is detected in NO.263 sample and NO.260 sample, respectively, and the failure is detected over 5 minutes ahead.

For a further discussion, the other variables in vector used for similarity calculation are investigated, and the results indicated that the deviations of the temperature of end-side bearings $x_{3}$ and current of driving motor $x_{6}$ lead to the similarity descend in the early stage of failure, as shown in Figure 10. The results indicate that failure information reflected by the other variables indicates the prognosis of failure.

Table 7. Comparison of different failure detection method.

\begin{tabular}{cccc}
\hline Method & Factor & Alarm 1 & Alarm 2 \\
\hline \multirow{2}{*}{$\begin{array}{c}\text { Vibration } \\
\text { Measurements }\end{array}$} & Threshold & $5.1 \mathrm{~mm} / \mathrm{s}$ & $5.1 \mathrm{~mm} / \mathrm{s}$ \\
\cline { 2 - 4 } & Current Value & $5.75 \mathrm{~mm} / \mathrm{s}$ & $5.20 \mathrm{~mm} / \mathrm{s}$ \\
\cline { 2 - 4 } & Sample Number & 124 & 276 \\
\hline \multirow{3}{*}{ Residual } & Threshold & $\pm 0.2385 \mathrm{~mm} / \mathrm{s}$ & $\pm 0.00625 \mathrm{~mm} / \mathrm{s}$ \\
\cline { 2 - 4 } & Current Value & $0.2492 \mathrm{~mm} / \mathrm{s}$ & $0.007 \mathrm{~mm} / \mathrm{s}$ \\
\cline { 2 - 4 } & Sample Number & $\mathbf{1 2 0}$ & 263 \\
\hline \multirow{3}{*}{ Similarity } & Threshold & 0.908 & 0.901 \\
\cline { 2 - 4 } & Current Value & 0.832 & 0.848 \\
\cline { 2 - 4 } & Sample Number & 121 & $\mathbf{2 6 0}$ \\
\hline
\end{tabular}

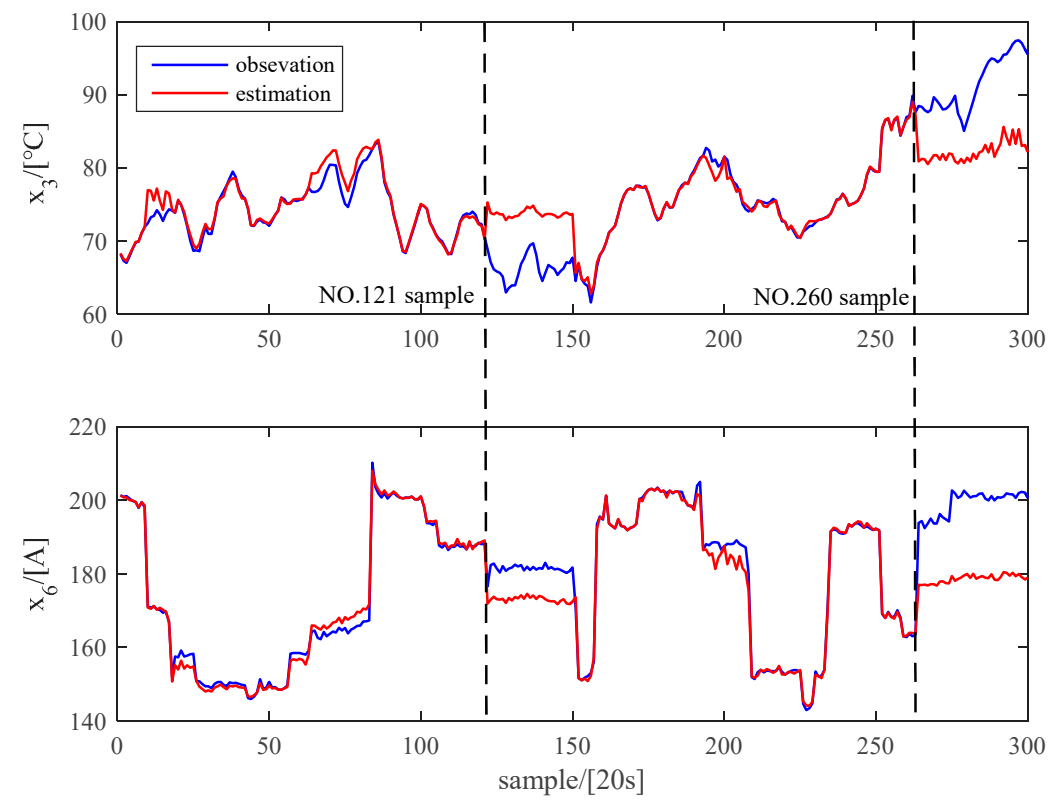

Figure 10. The trend of $x_{3}$ and $x_{6}$ while alarms.

\section{Conclusions}

An industrial equipment condition monitoring method based on MEST is proposed in this paper, and a novel method for construction of the memory matrix is put forward. The improved similarity that combines relative information in other variables is applied in monitoring. For different equipment and monitoring parameters, the method could be applied. The actual operational data for a blower fan in thermal power plant is used for validation, and the condition estimation performances are discussed. The actual data for failure event are used for validating the effectiveness of incipient failure detection 
employing proposed condition monitoring and early alarm method, the performance is compared with traditional exceed threshold method.

The method has advantages such as, it is concise and easy to understand conceptually, which should be attractive to industrial engineers. Irrespective of the steady or dynamic work condition, the proposed memory matrix construction method improves the accuracy of condition monitoring. The proposed method using residual and similarity enhances the alarm timeliness, and proposed method could identify the incipient failure ahead.

Although the proposed method has been employed in a specific blower fan, the model can be further explored with suitable parameters selection and threshold determination. The method should be further proved for different industrial equipment, and further research is planned for taking the method into account in other industrial equipment.

Author Contributions: D.L. proposed the idea and carried out the validation; H.Z. guided the research; F.H. collected the data. All authors have read and agreed to the published version of the manuscript.

Funding: This research received no external funding.

Conflicts of Interest: The authors declare no conflict of interest.

\section{References}

1. Hameed, Z.; Hong, Y.S.; Cho, Y.M.; Ahn, S.H.; Song, C.K. Condition monitoring and fault detection of wind turbines and related algorithms: A review. Renew. Sustain. Energy Rev. 2009, 13, 1-39. [CrossRef]

2. Wang, T.; Han, Q.; Chu, F.; Feng, Z. Vibration based condition monitoring and fault diagnosis of wind turbine planetary gearbox: A review. Mech. Syst. Sig. Process. 2019, 126, 662-685. [CrossRef]

3. Tavner, P.J. Review of condition monitoring of rotating electrical machines. IET Electr. Power Appl. 2008, 2, 215-247. [CrossRef]

4. Rusiński, E.; Moczko, P.; Odyjas, P.; Pietrusiak, D. Investigation of vibrations of a main centrifugal fan used in mine ventilation. Arch. Civ. Mech. Eng. 2014, 14, 569-579. [CrossRef]

5. Carden, E.P. Vibration Based Condition Monitoring: A Review. Struct. Health Monit. 2004, 3, 355-377. [CrossRef]

6. Ristivojevic, M.; Mitrovic, R.; Lazovic, T. Investigation of causes of fan shaft failur. Eng. Fail. Anal. 2010, 17, 1188-1194. [CrossRef]

7. Ruiliang, Z.; Xi, G.; Fengshou, G.; Wang, T.; Ball, A.D. Gear Wear Process Monitoring Using a Sideband Estimator Based on Modulation Signal Bispectrum. Appl. Sci. 2017, 7, 274.

8. Qingjun, W.; Chen, H.; Chen, X.; Yang, H.; Wang, G. Early fault detection of gearbox using weak vibration signals. Eksploat. I Niezawodn. Maint. Reliab. 2011, 49, 11-15.

9. Bolaers, F.; Cousinard, O.; Marconnet, P.; Rasolofondraibe, L. Advanced detection of rolling bearing spalling from de-noising vibratory signals. Control Eng. Pract. 2004, 12, 181-190. [CrossRef]

10. Singh, G.K.; Kazzaz, S.A. Induction machine drive condition monitoring and diagnostic research-a survey. Electr. Power Syst. Res. 2003, 64, 145-158. [CrossRef]

11. Ebersbach, S.; Peng, Z. Expert system development for vibration analysis in machine condition monitoring. Expert Syst. Appl. 2008, 34, 291-299. [CrossRef]

12. Dai, J.; Tang, J.; Shao, F.; Huang, S.; Wang, Y. Fault Diagnosis of Rolling Bearing Based on Multiscale Intrinsic Mode Function Permutation Entropy and a Stacked Sparse Denoising Auto-encoder. Appl. Sci. 2019, 9, 2743. [CrossRef]

13. Harrison, G.A. Neural Network Based Analysis System for Vibration Analysis and Condition Monitoring. J. Acoust. Soc. Am. 2001, 111, 1969. [CrossRef]

14. Kong, Z.; Tang, B.; Deng, L.; Liu, W.; Han, Y. Condition monitoring of wind turbines based on spatio-temporal fusion of SCADA data by convolutional neural networks and gated recurrent units. Renew. Energy 2020, 146, 760-768. [CrossRef]

15. Bangalore, P.; Letzgus, S.; Karlsson, D.; Patriksson, M. An artificial neural network-based condition monitoring method for wind turbines, with application to the monitoring of the gearbox. Wind Energy 2017, 20, 1421-1438. [CrossRef] 
16. Toh, G.; Park, J. Review of Vibration-Based Structural Health Monitoring Using Deep Learning. Appl. Sci. 2020, 10, 1680. [CrossRef]

17. Cempel, C. Optimization of symptom observation matrix in vibration condition monitoring. In Proceedings of the Reliability, Maintainability and Safety, 2009. ICRMS 2009. 8th International Conference on IEEE, Chengdu, China, 20-24 July 2009.

18. Gross, K.C.; Singer, R.M.; Wegerich, S.W. Application of a model-based fault detection system to nuclear plant signals. In Proceedings of the Office of Scientific \& Technical Information Technical Reports, Seoul, Korea, 6-10 July 1997.

19. Bockhorst, F.K.; Gross, K.C.; Herzog, J.P.; Wegerich, S.W. MSET modeling of Crystal River-3 venturi flow meters. In Proceedings of the Office of Scientific \& Technical Information Technical Reports, San Diego, CA, USA, 10-15 May 1998.

20. Guo, P.; Infield, D.; Yang, X. Wind Turbine Generator Condition-Monitoring Using Temperature Trend Analysis. IEEE Trans. Sustain. Energy 2012, 3, 124-133. [CrossRef]

(C) 2020 by the authors. Licensee MDPI, Basel, Switzerland. This article is an open access article distributed under the terms and conditions of the Creative Commons Attribution (CC BY) license (http://creativecommons.org/licenses/by/4.0/). 